mental state. The overall average age of $45 \%$ of all inpatients exceeds 65 years.

This hospital is now functioning on about 1.0 beds per 1,000 of the population served, and this figure has been achieved over the past 12 years by high turnover of short-stay beds, rigid control of geriatric admissions, but above all by the cutback in readmissions resulting from the support of discharged chronic psychotics and other recently discharged mentally ill persons with continuing social problems through the day unit. Over this period we have lost some 200 longer-stay patients but have built up a day patient force of almost the same number, though the individuals are not identical.

For each of the past five years we have found that, on average, we have finally accepted the obligation to take back into our long-stay wards on a permanent basis from 11 to 13 patients, all of whom were no longer capable of being supported within the community reinforced by the facilities of the day unit. Most of these people have a life expectancy of 30 years and all have at one time or another received every known and appropriate treatment. It will be at least 15 years before any of each small cohort is removed by death; there will thus be a steady accumulation of these patients.

The inescapable fact is that certain chronic psychotic patients ultimately become unacceptable in the community by reason of appearance, oddities, and vagaries of behaviour or because of frankly psychotic mental content. These patients, if they are not to become the appalling spectacles which haunt the London parks, undergrounds, and main-line stations, do require the kindly, understanding, and indeed free atmosphere of a long-stay psychiatric ward (which can be quite small and homely) where their needs are recognized and where each can be treated as an individual. Where then will they go when we have closed down the "asylum" which they require? The district general hospitals certainly won't, and will not be able to, deal with them; present indications are that they will also still be unacceptable to the ordinary residents of social welfare accommodation unless these authorities establish numerous little asylums, which would probably be non-viable.-I am, etc.,

St. Luke's Hospital,

MARTIN CUTHBERT

Middlesbrough, Teesside

\section{Intramuscular Injection and Coagulation} Defects

SIR,-I was extremely interested to read the letters from Dr. P. M. Jones (24 June, p. 770 ) and Dr. T. Dyk (30 December, p. 795) on the danger of intramuscular injections in patients with coagulation defects.

I have studied haematoma formation in chronic uraemic patients with bleeding tendency due to a uraemic haemostatic defect of the platelets. In these patients with normal platelet counts and prolonged Ivy bleeding time (over 10-15 min) large intragluteal haematomas never developed after intramuscular injections, and only prolonged oozing could be observed. During haemodialysis, however, intramuscular injections were always associated with excessive haematoma formation because of the heparin administration.

In my experience the danger of intramuscular injections is insignificant not only in thrombocytopenic states, but in uraemic toxin-induced thrombocytopathy as well.-I am, etc.,

County Hospital,
Miskolc, Hungary

S. BERKESSY

\section{Intestinal Pseudo-obstruction}

SIR,-I deplore the term "intestinal pseudoobstruction" and am surprised that it should be used in a leading article (13 January, $p$. $64)$; it is misleading and encourages the surgeon to ignore the underlying cause of the obstruction.

Intestinal obstruction may be acute, subacute, or chronic, the last two being incomplete obstructions. It may be due to a variety of causes, but the syndrome remains the same, depending on the level of the lesion and the degree of obstruction. The great majority of patients with obstruction will come to laparotomy, and if no macroscopic lesion is found may well be labelled as pseudo-obstruction and the underlying pathology ignored.

Patients are either completely or partially obstructed or not obstructed; there is no such condition as pseudo-obstruction. Do patients from whom a normal appendix is removed have pseudo-appendicitis or do we look for an alternative explanation for their symptoms? - I am, etc.,

JULIAN NEELY

Crawley, Sussex

\section{Administration of T.A.B.}

SIR,-While welcoming your intention to publish a series of articles on "A New Look at Infectious Diseases," I find it unfortunate that in the first of these (13 January, p. 98)

Dr. A. M. Geddes should suggest that the prevention of enteric fever should be by "two intradermal injections of $0.1 \mathrm{ml}$ " of T.A.B. The Standing Medical Advisory Committee for the Central Health Services Council as recently as July 1972 in the booklet Immunisation against Infectious Disease 1 have clearly set out (p. 15) that currently accepted practice in this field is to give T.A.B. by subcutaneous injection, the first dose being $0.5 \mathrm{ml}$ and the second $1 \mathrm{ml}$ injection. As the Committee point out, $0.1 \mathrm{ml}$ given by the intradermal route "may be too small a dose to confer adequate protection" and "it is inadvisable to attempt to administer a large volume by this route." They also state that "painful reactions have been reported following the administration of both . . . T.A.B. and typhoid vaccine by the intradermal route."

I am sure these comments would command general acceptance and I should be interested to learn on what gounds Dr. Geddes recommends only intradermal T.A.B.-I am, etc.,

ANGUS MCGREGOR

Department of Community Health

Southampton

1 Department of Health and Social Security. Immunisation Against Infectious Disease. London, D.H.S.S., 1972.

\section{Clinical Freedom in the N.H.S.}

SIR,-We have received a welcome document from Dr. Derek Stevenson, Secretary of the B.M.A., giving us assurances that the Council of the Association has been active in pressing for certain amendments to safeguard the position of doctors under the N.H.S. Reorganization Bill, due to come into effect in April 1974. (See Supplement, 3 February, p. 29.)

On the subject of clinical freedom, the Secretary points out that "the official report on management ${ }^{1}$ states that consultants and general practitioners must have clinical autonomy so that they can be fully responsible for the treatment they prescribe for their patients." While the term "treatment" may be interpreted here in its widest sense, it should not be forgotten that over $10 \%$ of all consultants in the N.H.S. (for example, radiologists, pathologists, and clinical physiologists) do not in point of fact prescribe treatment for patients, for they are wholly and responsibly engaged in carrying out specialist diagnostic procedures upon them. Certain of these diagnostic procedures may not, in themselves, be entirely without risk to the patient of subsequent morbidity.

In order to define the position of all groups of consultants in regard to clinical freedom without ambiguity, I should like to suggest an important amendment, namely, that "consultants and general practitioners must have clinical autonomy so that they can be fully responsible for the treatment they prescribe, and for such diagnostic procedures on patients as they may be required to undertake or supervise." - I am, etc.,

\section{Leeds \\ 1 Department of Health and Social Security Management Arrangements for the Reorganized
National Health Service. London, H.M.S.O., 1972}

K. A. EXLEY

\section{G.M.C. Inquiry}

SIR,-The Secretary of State for Social Services has announced his intention, in conjunction with the Lord President of the Council and the Secretaries of State for Scotland, for Wales, and for Northern Ireland, of setting up a committee of inquiry into the regulation of the medical profession, with the following terms of reference:

"To consider what changes need to be made in the existing provisions for the regulation of the medical profession; what functions should be assigned to the body charged with the responsibility for its regulation; and how that body should be constituted to enable it to discharge its functions most effectively: and to make recommendations."

The Council of the British Medical Association has referred the task of preparing evidence for the committee of inquiry to a special working party which consists of two panels. Panel A will deal with a wide range of matters covered by the terms of reference of the inquiry. Panel B will deal with the specific matter of disciplinary machinery.

The two panels have now met and have jointly decided to seek the views of branches and divisions and of the major committees of the Association on matters coming within the terms of reference of the committee of inquiry, and a letter of invitation has been sent to those concerned. The panels are also ready to consider comments from individuals, and the purpose of this letter is to invite any member of the Association who wishes to do so to submit his views in writing to the Secretary of the Association to reach him at B.M.A. House not later than Monday 19 March 1973. Any communications received after that date will be 